\title{
Criteria of meaningful stakeholder inclusion in internet governance
}

\author{
Jeremy Malcolm \\ Electronic Frontier Foundation, San Francisco, United States of America
}

Published on 16 Dec 2015 | DOI: 10.14763/2015.4.391

\begin{abstract}
Just as the so-called multi-stakeholder model of internet governance has attained broad acceptance, it has also begun to attract criticism for how elastic that term is, extending to processes that at best offer limited opportunity for meaningful stakeholder inclusion, and at worst may be a front for corporate self-regulation or government policy whitewashing. There is an apparent need for a set of criteria to distinguish these deficient processes from those that truly do promote policy-making that includes the perspectives of all affected stakeholders. This paper proposes such a set of criteria.
\end{abstract}

Keywords: Multi-stakeholderism, Internet governance

\section{Article information}

Received: 11 Aug 2015 Reviewed: 11 Nov 2015 Published: 16 Dec 2015

Licence: Creative Commons Attribution 3.0 Germany

Competing interests: The author has declared that no competing interests exist that have influenced

the text.

URL:

http://policyreview.info/articles/analysis/criteria-meaningful-stakeholder-inclusion-internet-governanc e

\section{INTRODUCTION}

This paper proposes a set of four criteria of meaningful stakeholder inclusion in global internet governance processes, that can simplify the process of examining and critiquing processes that purport to allow for public or multi-stakeholder involvement in public policy development. Because the criteria that will be presented here are largely independent, they allow for the multi-dimensional assessment of such processes. In comparison, the application of a binary designation "multi-stakeholder" conveys too crude a meaning, which has allowed its appropriation by a broad range of processes (Raymond and DeNardis, 2015, p. 575), some of which are not particularly open or participatory. This has even led certain people to assume that multi-stakeholder processes are necessarily undemocratic or captured, merely because some are. 
Redefining the term "multi-stakeholder" is not the answer to this, because although more detailed definitions have been offered, its natural and literal meaning is appropriately fairly limited: denoting policy processes which allow for the participation of the primary affected stakeholders, or groups of these who represent different interests (which is the baseline from which this document also proceeds). Neither is it particularly useful to fall back on catchwords like "open", "transparent" and "bottom-up" (although these are important characteristics of meaningfully inclusive multi-stakeholder processes), without considering the object that these characteristics serve. It is suggested here that such characteristics are not values in their own right, but are valuable to the extent that they facilitate a democratically legitimate governance process.

More specifically, the criteria of meaningful stakeholder inclusion presented here are designed to capture the extent to which the processes in question are effectively designed to incorporate the viewpoints of all affected stakeholders into the development of those policies in a balanced way, this being the essential feature from which this subset of multi-stakeholder processes can claim democratic legitimacy. Because it is very difficult to get this right, skepticism about multistakeholder processes in general is justified. But at the same time, there is little alternative to exploring such processes, given that despite pockets of internet policy that can be effectively governed locally, more often the border-crossing impacts of (or impacts upon) such regulation caused by the internet's global architecture impel stakeholders to coordinate in order to govern those issues effectively and legitimately.

\section{CRITERIA}

A useful starting point in assessing whether public policy processes that incorporate multiple stakeholders meaningfully include those stakeholders in those processes is to pose the following four questions:

1. Are the right stakeholders participating?

2. How is their participation balanced?

3. How are the body and its stakeholders accountable to each other for their roles in the process?

4. Is the body an empowered space?

Since institutions utilising multi-stakeholder processes tend not to directly address these issues, or do not do so in a way that easily allows them to be compared with other such institutions and processes, this paper is intended to supply a set of criteria that makes such comparison easier. These criteria are developed below.

\section{ARE THE RIGHT STAKEHOLDERS PARTICIPATING?}

A multi-stakeholder process does not begin to provide meaningful stakeholder inclusion unless the right stakeholders are participating, where "right" means that it should include sufficient participants to present all the perspectives of all with a significant interest in any policy directed at an internet governance problem.2 This means not only those who will implement the policy or be affected by its implementation, but also those whose knowledge or resources will be key to solving the problem, and those whose consent or cooperation is needed to clear the way for its effective implementation.3

This does not mean that all of the individually affected stakeholders must or should participate in the process. On the contrary, the fewer distinct interests that can feed into the process, the 
more smoothly it can be managed. Unlike in representative democratic processes with geographically bounded electorates, the interests of stakeholders in global internet governance decisions need not be toted up numerically.4 Thus questions commonly asked by critics of multi-stakeholder processes about how stakeholders are "enfranchised" (for example, one stakeholder one vote, or some sort of proportional representation) miss the point, as other methods are used to balance stakeholders' perspectives (see 2 below).

In most cases, this involves aggregating the perspectives of participants with similar interests into stakeholder groups. This induces similarly-placed stakeholders to cooperate and to selforganise around a collective view, thereby much simplifying the later task of balancing stakeholders' views.5

Globally, such stakeholder groups may be as broad as "governments", "industry" and "civil society", or it may be that any or all of those stakeholder groups need to be further sub-divided or, conversely, collapsed. The World Intellectual Property Organization (WIPO) - although not a good example of meaningful stakeholder inclusion - demonstrates both of these cases, in that it includes several distinct groups of governments, yet treats the private sector and civil society as a single stakeholder group. Cross-cutting groups of stakeholders that run across the traditional categories may also exist; the internet technical community, as recognised by the Internet Governance Forum (IGF), Organisation for Economic Cooperation and Development (OECD) and Commission for Science and Technology for Development (CSTD), is the most obvious example.

As Gasser, Budish and West (2015, pp. 18-19) have found, it follows that there is no single correct set of stakeholder groups. The most convenient grouping will depend upon a range of factors including the issue or issues to be dealt with, the history of governance of these issues and of the actors involved in dealing with them, and the working methods that are to be adopted in developing and implementing solutions. For this reason establishing a set of groups or constituencies (or several sets of them) that most smoothly facilitate the governance process can be an imprecise and iterative process, and this paper does not attempt to systematise that process.6

However the incorrectness of a set of stakeholders can often be determined experientially. Stakeholders who represent new perspectives may emerge and demand involvement, or an existing stakeholder group with diverse internal perspectives may exhibit pressures towards division. Thus, without attempting to propose positive specifications for institutional mechanisms to forestall or respond to these pressures, it can nevertheless be posited that any multi-stakeholder process that desires to meaningfully facilitate the inclusion of stakeholders should be open enough to admit new participants, and dynamic enough to adapt its structures and processes to include their perspectives in a way that meets with the approval of the community of stakeholders at large.

Not directly addressed by this is the question of how the stakeholders are defined and selected, and by whom? Although, again, no attempt is made to specify the procedural minutiae here, by the very nature of how a multi-stakeholder process works, this has to be a consensus-based process. The facilitation of this consensus may be led by a single stakeholder group or by the staff of the body, but all the participating stakeholders will ultimately have to accept that the structure is fair and balanced, or they will withdraw their participation, leaving the remainder with an apparent deficit of legitimacy that will render the outputs of the process less persuasive.7

The absence of participation of stakeholders who are integral to the resolution of an internet 
governance problem does not always reflect a deficit in the perceived legitimacy of the process. Their failure to participate may also be due to lack of resources, lack of familiarity with the issues of the forum in which they are discussed, or due to cultural or linguistic differences. All of these must be bridged through proactive outreach and resourcing, and an institution's ability to address these needs is often one of the deciding factors as to whether it can achieve inclusive stakeholder participation or not.8

As a first step towards achieving meaningful stakeholder inclusion, it is suggested to apply the following criterion as to whether the right stakeholders are participating in a multi-stakeholder internet governance process:

The body should have access to the perspectives of all those with significant interests in a policy problem or its possible solutions.

Strategies that a body can pursue to ensure that it meets this criterion include:

- Being structurally and procedurally open to admit the participation of all stakeholders who self-identify as being significantly interested, in an internet governance policy problem or by the possible solutions to that problem that are within its mandate.10

- A programme of resourcing and outreach to ensure that the perspectives of all those stakeholders who are significantly affected by that problem or those solutions are indeed included.

- Flexibility to adapt its internal structures and processes to accommodate stakeholders within groupings that facilitate the work of the body, and can be consensually accepted by all participants as being fair and balanced.

\section{HOW IS THEIR PARTICIPATION BALANCED?}

One of the most important insights of the NETmundial Multistakeholder Statement was that there are no uniformly appropriate roles for stakeholders in internet governance, being such a broad regime covering a range of issues.11 This amounts to a critique of a simplistic "equal footing" multi-stakeholder model, that would require the perspectives of participating stakeholders to be weighted equally (Doria, 2014, p. 123).12

While all interested stakeholders do have an equal right to participate, it will seldom be appropriate to consider all views with the same weight, because their interests may well be engaged to different degrees, they may have different levels of expertise, and different sources of legitimacy that may require one stakeholder's input to be given greater weight than another's. For example, when setting cross-border standards for consumer privacy (as the OECD, for example, does), it is appropriate to take into account the perspectives of a company like Facebook, that monetises consumers' data, but inappropriate for those perspectives to trump those of governments and transnational civil society.

Thus it is a fallacy to assume that multi-stakeholderism necessarily involves putting governments in a subordinate role, or requires treating the private sector as an equal stakeholder with others, or allows an objection by any stakeholder to veto the development of a policy recommendation.13 In practice, such an inflexible arrangement allows governance to be held hostage to minority interests.14

How, then, should the perspectives of different stakeholders be balanced, and by whom? There are two main ways in which this can be done: through policy development processes designed to roughly balance the views of stakeholders ex ante (but usually subject to a formal decisiontaking process by a governing council), or by a deliberative democratic process in which the roles of stakeholders and the balancing of their views are more dynamic (though might again be 
subject to a formal decision taking process, which may be situated elsewhere, and/or be distributed). Some multi-stakeholder processes may also combine these two models.

The first, which could be called the constituency model, is conceptually simpler and therefore the most common, but also the most politically fraught and vulnerable to capture. It is best suited to a body that deals with a narrow range of issues that can conveniently be considered by the same stakeholder groups using defined structures and processes (see question 1). To the extent that these structures and processes leave a degree of discretion in the final decisiontaking, it also depends upon a degree of trust being placed in the putatively impartial or stakeholder-balanced governing council that will exercise that discretion, which in turn places a high burden upon the body's accountability to the stakeholders (see question 3 below).

The second way to balance the perspectives of the stakeholders is the deliberative model. Democratic deliberation aims towards achieving a rational consensus through a process of public reasoning by stakeholders couched in terms of the common good, rather than private self interest or, particularly, exogenous political or economic power. The challenges of the deliberative model are no less than that of the constituency model, but they are different challenges. Rather than front-loading the process of balancing stakeholder views into the design of the institution's structure (and placing much trust in the governing body to play fair when it makes a final decision), a lot more work must be done in the design and facilitation of a policy development process that allows the stakeholders to become well-informed while eliminating power imbalances. Because this is a more novel approach, fewer good examples of it exist; however, the NETmundial meeting was one notable attempt (Varon, 2014), the IETF has also been described as utilising a deliberative process - notably without pre-defined stakeholder groups (Froomkin, 2003), and the IGF has also begun to experiment with deliberative structures for its 2015 meeting, including a Deliberative Polling side-event and a methodology for providing feedback on the outputs of Dynamic Coalitions.15

Either way, a multi-stakeholder process that is not systematically designed to eliminate the massive power imbalances between stakeholders can become an instrument of domination by the powerful. It is worse if these imbalances are exploited during the design of the institution's decisional structures and accountability mechanisms, because in that case those power imbalances can become self-perpetuating. This is why multi-stakeholder processes have come under much criticism from some who fear that corporations will entrench their positions of power and abuse those processes to overpower the public interest-particularly if the role of governments is not structurally elevated over those of all other stakeholders. Similarly, there is concern that the security and economic interests of certain governments can be (as, indeed, those of the United States have been) structurally cemented in what are notionally multistakeholder internet governance processes.

The flattening of power imbalances, which is intrinsic to deliberative democratic processes, is also absolutely critical to multi-stakeholder processes of all kinds, if they are to promote meaningful stakeholder inclusion in internet governance. Yet while there are many examples of how to do this, there is no single template that will serve all bodies best. Thus this document does not prescribe in detail how workflow and agenda work, how consensus is assessed, how committees are structured, what online tools or meeting methodologies should be used, and so on. Instead the following more general criterion is proposed, along with some examples of how it may be advanced:

There must be mechanisms to balance the power of stakeholders to facilitate them reaching a 
consensus on policies that are in the public interest.

The ways in which this can be done include:

- As a first pass, agreeing upon any unique roles of the participating stakeholders in respect of the policies under consideration, based on all relevant factors including historical roles, expertise and resource control.

- Thresholds for decision-making, such as rough consensus, that give all stakeholders an effective voice in developing policy, while minimising the possibility of minority veto or capture by the powerful.

- Deliberative processes that flatten power differences between stakeholders and require them to defend their position in terms of their view of the public interest.

\section{HOW ARE THE BODY AND ITS STAKEHOLDERS ACCOUNTABLE TO EACH OTHER FOR THEIR ROLES IN THE PROCESS?}

Integral to any multi-stakeholder process that produces outcomes is the need for trust that the host body will actually uphold its responsibility to fairly balance the perspectives of participating stakeholders. Conversely, the body must have trust that the stakeholders can claim a legitimate interest to contribute the perspectives that they do. Thus, to more fully express this question, it asks how accountable the body is to stakeholders for the authority that it exercises, and how accountable the stakeholders are to the body (and to each other) for the legitimacy of their participation.

Taking the authority of the body first, this may be drawn from various sources other than being derived from the stakeholders themselves, usually recorded in some kind of constitutional document. It may be a pre-existing institutional authority such as the United Nations.16 Similarly, it may claim democratic legitimacy, as in the case of an elected national government that leads a multi-stakeholder consultation (though this would usually be better described as an example of participatory democracy). Or it may have a free-standing authority drawn from the consent of the stakeholders.17 Whatever the source of its authority, if the stakeholders do not accept its exercise (in functions such as formal decision-taking or stakeholder selection), the body cannot function.

Assuming that the authority of the body over its stakeholders is accepted, in order to maintain that authority it must also embed various well-understood mechanisms of accountability to them. For example, the body must operate transparently, it must be internally accountable in its adherence to process, it must be subject to some form of independent external oversight or review, and so on (Weber, 2009).

By the same token, there are various bases on which stakeholders can demonstrate their legitimacy to participate in a particular stakeholder group that has been accepted as possessing a significant interest in the policies under discussion (see question 1).18 Where governments have been accepted as stakeholders, their institutional or sovereign authority to participate in that capacity should be fairly easily demonstrable. Stakeholders who may claim to be in some other way representative of the views of a broader public, as civil society does, have various ways of demonstrating that, such as a membership structure and internal elections for self-selection of representatives.19 Those who claim involvement because of their technical expertise, as the academic and technical communities do, can likewise provide evidence of this as a condition of their participation.

The level of documentation of these claims of legitimate membership as a stakeholder will vary from nil (for example the contributions of participants at the IETF, from a 14 year old bedroom 
hacker to a university professor, are assessed on merit), to self-assessment (as at the IGF), to formal vetting (to achieve accreditation by the United Nations Economic and Social Council (ECOSOC) requires civil society stakeholders to provide substantial documentary evidence of their activities). It has been suggested that transparency of sources of funding of participants could also be required of participants in a multi-stakeholder internet governance process (Belli, 2015); this may be particularly important where there is a risk of capture or undue influence.

To the extent that objective assessment of stakeholder claims is possible, transparency of the facts that underlie those claims is imperative. On the other hand, it cannot be the role of every multi-stakeholder process to vet the various claims of legitimacy of every actor who participates in the process, as not only would this be resource-intensive, but is also ultimately largely redundant, as the legitimacy of the process is not drawn only from that of its participants, but also from the accountability and transparency of the body's own processes as well as from the acceptance of its outputs by the broader community of stakeholders.2o

It should also be noted that public rationality of a deliberative process acts as a further safeguard against the capture of that process by a few misidentified or otherwise "bad" actors (see 2 above). This is a further point counting in favour of the deliberative rather than the constituency model.

In summation, the criterion relevant to the question posed above can be couched in the following terms:

\section{Mechanisms of accountability must exist between the body and its stakeholders to demonstrate the legitimacy of their authority and participation respectively.}

The factors involved in determining whether this is so include:

- Where the body exercises any authority over the stakeholders, its legitimacy to do so (whether institutional, democratic, meritocratic, or otherwise) must be generally accepted by the community of stakeholders at large.

- The body must operate transparently and adopt mechanisms of accountability that are recognised as organisational best practices, such as independent review.

- The process must include means by which the stakeholders can be held accountable for the legitimacy of their participation, as appropriate to the process and their roles in it.

\section{IS THE BODY AN EMPOWERED SPACE?}

The fourth and final question bears upon how "meaningful" is the stakeholder inclusion in an internet governance process, where meaningfulness is a function of how closely the stakeholder's participation is linked to empowered spaces in which authoritative mutual decisions are made, as opposed to public spaces that are limited to discussion (Haristya, forthcoming). The body might not be an empowered space in itself, but might be effectively (and usually formally) linked to other empowered spaces, which can also make participation in the former meaningful to some degree; amongst these processes, some may lay claim to being multi-stakeholder, while others might not. However a body which is neither empowered in its own right, nor effectively linked to empowered spaces, is not accurately described as a multistakeholder process, and certainly not as one that provides meaningful stakeholder inclusion in internet governance.

An example of a multi-stakeholder process that is an empowered space in its own right is ICANN, which, by means of the participation of its stakeholders, directly makes policies about the global domain name system (DNS). The OECD Recommendation on Consumer Policy 
Decision Making describes a multi-stakeholder process that is not directly empowered, but which is formally linked to empowered spaces, in the following terms:

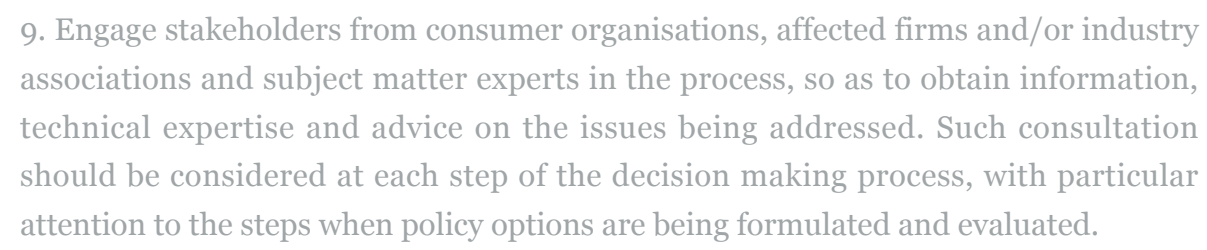

Thus in the case being described, the OECD member's national lawmaking processes are the empowered space, to which the consultations with non-governmental stakeholders are formally linked.

An example of a body that has been found not to be well linked to any empowered spaces is the IGF,21 which in its historical format-and as a result of quite deliberate interventions by certain private sector and governmental stakeholders who desired to limit its political influence (Malcolm, 2008, pp. 423-431) - has been effectively limited to the status of a discussion forum. As noted above, ongoing experiments with the IGF's format may however see it strengthening its link to empowered spaces in the future.

Each of the other three questions posed above suggests an answer that advances meaningful stakeholder participation (involving more interested stakeholders is better than fewer, having mechanisms to balance their views fairly is better than not having them, and more accountability is better than less). But this question is presented more openly, since even amongst civil society, the "best" answer is contingent on one's view of how closely nongovernmental stakeholders should be linked to empowered spaces.

For some, multi-stakeholder processes can and should be directly empowered to make or to implement global internet governance policies. But for others, there are concerns about multistakeholder processes that directly effect changes in global governance, particularly outside of the technical and administrative realm.

These concerns are heard from both the political left and the right. From the left, they have manifested in a rejection by some of multi-stakeholder processes in general, to the extent that these lack the intermediation of more traditionally representative democratic institutions such as national governments, or intergovernmental bodies such as the United Nations (Gurstein, 2014). This in turn stems from a distrust of providing corporations with a pervasive role at (and behind) the negotiating table, as this is seen as effectively corporate self-regulation under another name, and therefore a diluted pacifier to much needed action (by governments).

The right on the other hand has no great love of regulation, and so while expressing support for the multi-stakeholder model, has been wary of accepting it as a method of policy development. For example, some private sector stakeholders have been amongst those most resistant to the IGF developing the capacity to produce even non-binding recommendations, since this would complicate the existing structures of power and influence by which corporations and governments craft policy in less open fora, or act in default of policy (Malcolm, 2008, p. 425).

This paper seeks to address these concerns by breaking the essential features of effectively inclusive processes into several criteria, and in particular by separating out this last criterion, 
which isolates the core concern of these critics. The extent of the disagreement can be further narrowed by breaking the process of internet governance into several stages, such as framing and agenda setting, drafting, validation of outputs, implementation and dispute resolution (de la Chapelle, 2011). Most of the concerns about overreach of multi-stakeholder processes could be resolved by limiting the empowerment of those processes to the stages of framing and drafting.22 And indeed, those are the stages to which almost all multi-stakeholder processes outside of the technical and administrative are already limited.23 Over time as multistakeholder processes mature and prove themselves, we can expect their adaptation to use in later stages of governance, including outside of the technical realm, to become less contested and for this limitation to be relaxed.

Meanwhile, it is important that the stages of the governance process in which the body is empowered be linked to other institutions with authority to execute the stages for which it is not empowered, in order for the inclusion of stakeholders in those earlier phases to be meaningful. This criterion is framed here in a way that is neutral as to exactly where to draw the dividing line between being the body directly empowered, and being linked to external authoritative empowered institutions:

For each stage involved in governance, the body should either be directly empowered to execute it, or linked to external institutions that have the authority to do so, as appropriate.

This requires, for example, the following:

- The body should develop a shared understanding of the extent of its own legitimate authority (that may vary by issue, stage of governance, implementation mechanism, and over time).

- At every point where the body lacks either the capacity or the authority to act, formal or informal two-way liaison mechanisms linking its outputs to external empowered institutions should exist.

- To facilitate this, the outputs of the body should be collected, synthesised, recorded and delivered in clear, actionable forms.

\section{CONCLUSION}

Amongst the important criteria that differentiate a self-styled multi-stakeholder process from one that actually promotes meaningful stakeholder inclusion in internet governance, the following have been suggested:

- The body should have access to the perspectives of all those with significant interests in a policy problem or its possible solutions.

- There must be mechanisms to balance the power of stakeholders to facilitate them reaching a consensus on policies that are in the public interest.

- Mechanisms of accountability must exist between the body and its stakeholders to demonstrate the legitimacy of their authority and participation respectively.

- For each stage involved in governance, the body should either be directly empowered to execute it, or linked to external institutions that have the authority to do so, as appropriate.

It is not suggested that the above criteria are the only relevant ones for assessing the legitimacy and effectiveness of governance processes that include multiple stakeholders.24 However, it is hoped that the application of these criteria does provide a modest advance on the status quo in which multi-stakeholderism is too frequently portrayed as an unalloyed good (or evil). Applying these criteria as a standard can assist to differentiate between notionally multi-stakeholder processes that wildly differ in how open, inclusive and democratically legitimate they really are. 
No claim is made that meaningful stakeholder inclusion in internet governance is easy to achieve, or that if achieved, it will easily resolve all internet policy problems. In particular, distributional effects of existing power structures are all-pervasive and these cannot be ignored. Inclusive stakeholder participation will not fully negate these imbalances.25 However, to the extent that multi-stakeholder processes score highly against the criteria presented here, they are less likely to have negative distributional effects than existing, less-inclusive governance institutions and processes that afford greater control over the global internet to overreaching national sovereigns and near-stateless global monopolists alike.

Civil society's agency in the ongoing process of the improvement of multi-stakeholder processes should not be dismissed. Doubtless, some compliant civil society actors have at times been coopted into unproductive discussions under the guise of multi-stakeholderism. On the other hand, the subset of multi-stakeholder processes that promotes meaningful stakeholder inclusion is one of the first and only governance innovations with the promise of truly empowering internet users. Until now, mass protest has probably been the most effective option for advancing civil society interests at the global level, especially in promoting transnational civil society interests that are otherwise unrepresented even in domestic politics (Losey, 2014). The evolution of mechanisms for their meaningful inclusion in multi-stakeholder internet governance processes provides a second, inside-track option for civil society to promote change.

By advancing these criteria it is hoped to help to establish a gold standard or "quality seal" of multi-stakeholder internet governance processes that provide the opportunity for meaningful stakeholder inclusion, allowing a more nuanced understanding of which such processes truly do further the global public interest, and which are just window-dressing of a government or corporate agenda. 


\section{REFERENCES}

Belli, Luca. (2015). A heterostakeholder cooperation for sustainable internet policymaking. Internet Policy Review 4 (2). DOI: 10.14763/2015.2.364.

http://policyreview.info/articles/analysis/heterostakeholder-cooperation-sustainable-internetpolicymaking.

Bradshaw, Samantha and DeNardis, Dr. Laura and Hampson, Fen Osler and Jardine, Eric and Raymond, Mark (2015). The Emergence of Contention in Global Internet Governance. Global Commission on Internet Governance Paper Series, 17. Retrieved from

http://ssrn.com/abstract=2634604.

Bray, Daniel and Slaughter, Stephen (2015). Global Democratic Theory: A Critical Introduction. New York: John Wiley \& Sons.

CSTD (2014). The mapping of international Internet public policy issues. Geneva. Retrieved from

http://unctad.org/meetings/en/SessionalDocuments/CSTD_2014_Mapping_Internet_en.pdf.

Doria, Avri (2014). Use [and Abuse] of Multistakeholderism in the Internet. In Radu, Roxana, Chenou, Jean-Marie and Weber, Rolf (eds) The Evolution of Internet Governance: Principles and Policies in the Making. Geneva: Springer.

Dryzek, J. S., \& Stevenson, H. (2011). Global democracy and earth system governance. Ecological Economics, 70(11), 1865-1874.

Eckersley, Robyn. (2012). Moving Forward in the Climate Negotiations: Multilateralism or Minilateralism? Global Environmental Politics 12, no. 2, 33.

Franda, Marcus F. (2001). Governing the Internet: The Emergence of an International Regime. Boulder: Lynne Rienner Publishers.

Froomkin, Michael A. (2003) Habermas@Discourse. Net: Toward a Critical Theory of Cyberspace. Harvard Law Review, 116(3), 749-873.

Gasser, Urs and Budish, Ryan and West, Sarah Myers (2015). Multistakeholder as Governance Groups: Observations from Case Studies. Berkman Center Research Publication, 2015-1.

Retrieved from http://ssrn.com/abstract=2549270.

Gurstein, Michael (2014) Democracy OR Multi-stakeholderism: Competing Models of Governance. Retrieved from https://gurstein.wordpress.com/2014/10/19/democracy-ormulti-stakeholderism-competing-models-of-governance/

Haristya, Sherly. (forthcoming) The roles of the civil society in developing and shaping deliberative system of the global Internet governance.

de La Chapelle, Bertrand (2011). Multistakeholder Governance - Principles and Challenges of an Innovative Political Paradigm. MIND 1, no. 2, 14-27.

Losey, J. (2014). The Anti-Counterfeiting Trade Agreement and European Civil Society: A Case Study on Networked Advocacy. Journal of Information Policy 4:205-227.

Malcolm, Jeremy. (2008). Multi-stakeholder Governance and the Internet Governance Forum. 
Perth: Terminus Press.

Raymond, M. and DeNardis, L. (2015). Multistakeholderism: Anatomy of an Inchoate Global Institution. International Theory, 7:572-616.

Varon, Joana (2014). The NETmundial: An Innovative First Step on a Long Road. In Drake, William J and Price, Monroe (eds) Beyond NETmundial: The Roadmap for Institutional Improvements to the Global Internet Governance Ecosystem. Geneva: Centre for Global Communication Studies, 16-24.

Weber, Rolf H (2009). Accountability in Internet Governance. 13 International Journal of Communications Law and Policy 152.

\section{FOOTNOTES}

1. The term "meaningful" used here alludes to its use in the NETmundial Multistakeholder Statement (further referenced below), which asserts that "There should be meaningful participation by all interested parties in internet governance discussions and decision-making, with attention to geographic, stakeholder and gender balance in order to avoid asymmetries." Although the term is not further defined there, this paper appropriates that term in an attempt to imbue it with meaning in the form of the criteria developed here.

2. CSTD (2014) provides a useful and lengthy, though still not exhaustive, survey of the scope of the field of internet governance, which exemplifies the kinds of policy issues or problems with which this paper is concerned.

3. To give a parallel example of the problem of climate change, Eckersley (2012) has defined a standard of "common but differentiated representation" which requires the participation of the parties who are the most capable in solving the problem, those who are most responsible for it, and those who are most vulnerable or affected by it. Transferring this to the internet governance context, Belli (2015) describes a similar "heterostakeholder" approach, which downplays the "sole reliance on the multiplicity of stakeholders rather than focusing on the heterogeneity of stakeholders' interests”.

4. This is of course not to say that there are no internet governance processes in which internal elections are held; the Internet Corporation for Assigned Names and Numbers (ICANN) and the Internet Engineering Task Force (IETF) provide some examples of this.

5. Having said this, there is a narrow category of cases, exemplified by the IETF, where the formal aggregation of interests into stakeholder groups has been found unnecessary for the effective resolution of technical problems. To avoid the risk of capture, this generally also requires a deliberative democratic process-see question 2.

6. But see question 3 below as to the accountability mechanisms required to guard against stakeholder groupings acting in illegitimate, unrepresentative ways.

7. Case studies of this include the NETmundial Initiative (see further Bradshaw et al. (2015), 7), and various supposedly multi-stakeholder processes at the national level, such as the Licenses for Europe initiative and various US National Telecommunications and Information Administration (NTIA) privacy multi-stakeholder processes.

8. Conversely, does this mean that any stakeholder (or group of stakeholders) that demands 
inclusion in a multi-stakeholder process should be recognised and afforded a say, provided only that the others consent? Not quite; they will also have to be accountable to the body for their claimed interest in the process, in order that the legitimacy of their participation can be demonstrated to the community of stakeholders at large, and any competing claims of interest can be resolved in a rational and consensual manner-question 3 below addresses this.

9. There is nothing in this test of significant interest that is specific to the internet governance context, but see generally Bray and Slaughter (2015), p. 68 and the works there cited.

10. As noted in the previous footnote, this is subject to those stakeholders' accountability for their self-identification as described in question 3 below.

11. "The respective roles and responsibilities of stakeholders should be interpreted in a flexible manner with reference to the issue under discussion." (NETmundial Multistakeholder

Statement, p. 6).

12. Anyway, paragraph 69 of the Tunis Agenda only talks about governments participating in internet governance on an equal footing with each other.

13. A power of mutual veto may be appropriate in some cases, where the need for full consensus arises from the ability for one stakeholder to undermine a measure to which they have not agreed (Malcolm, 2008, p. 294). This can also help to balance existing power disparities between stakeholders-given that the most powerful, such as governments, have an effective power of veto over measures they don't like anyway. But not all multi-stakeholder processes recognise such a veto right, and it is not an essential element of all such processes; for example, the US government, although disagreeing with ICANN's decision on the .xxx domain, forebore from overriding it.

14. For example, consider the parallel context of Hong Kong's "functional constituencies", which are akin to stakeholder groups, and which have given outsized weight to the views of constituencies with no legitimate interest in a given issue.

15. The IGF's Dynamic Coalitions are self-organised issue-based working groups. Until now, there had been no mechanism for the IGF to provide any form of validation of the outputs of these groups.

16. For example, at the IGF, the United Nations Department of Economic and Social Affairs (UN DESA) exercises authority in appointing members of the Multi-stakeholder Advisory Group (MAG). Similarly the OECD's governmental members define processes for other stakeholder groups (CSISAC for civil society, BIAC for business and TUAC for trade unions) to provide their input into its work.

17. Examples include the meritocratic Internet Architecture Board (IAB) which is selected by a nominating committee, and the ICANN Board, which is multi-stakeholder in its own right, with a balance of elected and appointed positions in a certain agreed constituency structure.

18. Belli (2015) suggests several bases for the legitimacy of stakeholder participation including "discursive" (for civil society actors who reflect social values) and "resource control" (for private sector actors' whose participation is necessary), whereas Malcolm (2008, pp. 147-157) describes at some greater length the various bases of legitimacy of the participation of the three categories of stakeholder recognised by the World Summit on the Information Society (WSIS)-civil society, private sector and government. 
19. "Representation" in this broad sense does not necessarily imply that the stakeholders have been selected democratically, but that they can demonstrate their connection in some way to those whose interests they are advancing in the policies under discussion; and there are various ways in which they might do that (Franda, 2001, p. 70).

20. Haristya (forthcoming) argues that the democratic legitimacy of global deliberative processes is a compound concept incorporating input, throughput, and output legitimacy, where input legitimacy is drawn from the incorporation of a diversity of discourses into the process, process legitimacy from the accessibility, transparency, accountability and inclusiveness of the process, and output legitimacy from the acceptance of the process or its result.

21. The UN Secretary-General's note on the first renewal of the IGF's mandate observed "that the IGF had not provided concrete advice to intergovernmental bodies and other entities involved in Internet governance," and "that the contribution of the IGF to public policy-making is difficult to assess and appears to be weak."

22. However there can be no a priori limitation of the legitimacy of multi-stakeholder processes to those stages, because many internet governance issues are not governed (or not only governed) through legal rules. For many core internet governance issues including online privacy, cyber security, and access, there are mechanisms of governance-such as technical standards development, the inculcation of community norms, and private investment in online infrastructure-that do not depend upon governmental validation, implementation or enforcement.

23. For example, Brazil's Marco Civil was drafted in an open, participatory and multistakeholder process, yet it was validated (passed into law) by the Brazilian parliament, and its implementation and enforcement is also largely (but not exclusively) a matter for government.

24. See further de La Chapelle (2011) and Belli (2015).

25. Debate also remains open as to the extent to which they should be eliminated, in this or other forms of global governance; against which arguments of conservatism, efficiency and pragmatism might be raised. 